\title{
Investigating the potential for the development of a just-in-time knowledge management model
}

\author{
P.D. Steyn and A.S.A. du Toit* \\ Centre for Information and Knowledge Management, University of Johannesburg, \\ PO Box 524, Auckland Park 2006, Republic of South Africa \\ adutoit@uj.ac.za
}

Received March 2009

\begin{abstract}
There have been numerous approaches to knowledge management over the past number of years. The term Just-in-Time (JIT) can be defined as a production or inventory scheduling technique found within the more complex production logistics disciplines. JIT is more appropriately thought of as a philosophy, as it is more than a mere set of management and production principles. JIT knowledge management is an endeavour to provide the right knowledge at the right time to the right person. This requires insight into the knowledge demand and supply process as well as the time horizon applicable to the knowledge required. Over the longer term business forecasts, environmental scans and strategic planning can be applied to close the gap between these variables. However, it is in the short term and in the satisfaction of immediate requirements that the present systems fail and management concerns are emphasised. JIT knowledge management seeks an optimisation of the matching process between demand and supply of knowledge within enterprises, i.e. it endeavours to translate the logistic concept of JIT to the knowledge management field. In addition to JIT knowledge management the concept of real-time knowledge management is introduced as an alternative, since present research indicates that the implementation of JIT knowledge management presents major challenges in terms of cost and development effort, restricting its use to mission critical applications. A more generic application of JIT knowledge management needs to be developed and it is contended that real-time knowledge management fits the requirements of enabling the enterprise to be agile in respect of its ability to respond to knowledge demands and to be sensitive to future knowledge requirements.
\end{abstract}

*To whom all correspondence should be addressed.

\section{Introduction}

Recent thinking on knowledge management has distinguished between demand-side knowledge management and supply-side knowledge management. The supply side of knowledge management is associated with the 'deliveryoriented' assumptions that valuable knowledge exists within the enterprise and that it is the task of management to find it, codify it and place it into a repository. This is then followed by an approach which 'decrees' and determines how it is to be distributed and to whom. Demand-side knowledge management is initiated through an approach requiring a view of where valuable knowledge exists within the enterprise and how knowledge can be used to the enterprise's competitive advantage. According to Yang (2007: 84) knowledge sharing and knowledge integration are key factors in achieving a competitive advantage. He argued that "companies can change from a situation where lost knowledge causes intellectual liabilities to a situation where shared knowledge results into intellectual assets”.

From an evolutionary perspective, the effort to increase productivity has been uppermost in the view of management and others. The principles of Taylorism have been refined, redeveloped and expressed in a number of ways from 'Task Analysis' to 'Industrial Engineering', and the like. Whether the approach to improve productivity considers the car production line at Ford in 1914 or modern productivity concepts such as continuous improvement (Kaizen) or Just-in-Time (JIT), the basis is the work done by Taylor (Drucker, 1999: 81).

The effort in the $21^{\text {st }}$ century will be to shift the emphasis from the manual worker, as we know how to improve the latter's productivity, to improving the productivity of the knowledge worker. This is considered a central challenge to management, as knowledge workers constitute at least $20 \%$ of the work force and are "rapidly becoming the largest single group in the work force of every developed country" (Drucker, 1999: 83).

The question may be posed as to the importance of knowledge management and its contribution to the competitive position of enterprises and further to those of industries and beyond to that of nations. There are a number of reasons, which collectively reflect the state of present-day knowledge management and the importance thereof (IBM, 2004: 22), namely:

- Knowledge has become a primary factor of production supporting the traditional factors of labour, land and capital. 
- The delivery of services has become a major value driver.

- Knowledge is a networked activity and thus utilises the efforts of many and is also able to capitalise on the collaborative effort of the participants.

- The digitisation of knowledge has enhanced its distribution, storage and transfer.

- Knowledge has the ability to cope with a dynamic environment and encapsulate innovation and technology in assisting it in the process.

The purpose of this article is to determine whether it is possible to implement a JIT knowledge management model analogous to the principles employed in the logistics JIT approach at a technology-oriented enterprise in South Africa. Such an approach needs to take cognisance of the present perspectives of enterprises on the nature and contribution of knowledge management and the exploratory nature, at this stage, of any initiative relating to JIT knowledge management due to the lack of actual working examples and the purely theoretical nature of some of the research done to date. The researchers are aware of one successful implementation of a JIT knowledge management initiative, which has been well documented by Davenport and Glaser (2002) and is used in this research study. However, the overall purpose of the research is to gain insight into what such JIT knowledge management should constitute. If it proves not to be practically executable in the enterprise, the purpose is to determine whether a larger incorporation of real-time knowledge management principles will yield a more workable solution to the current enterprise perspective on the role and contribution of knowledge management.

\section{Demand and supply-side knowledge management}

Knowledge plays a crucial role in the competitive nature of enterprises and hence constitutes a critical component of enterprise strategy. Bateman and Snell (2007:9) define knowledge management as practices to discover and harness the intellectual resources of an enterprise embodied by the individuals employed by the enterprise. The aim of such a knowledge management definition is to find, unlock, share and capitalise on the expertise and skills of employees. Snowden (2000:8) defines knowledge management as "the identification, optimisation and active management of intellectual assets, either in the form of explicit knowledge held in artefacts or as tacit knowledge possessed by individuals or communities”. Ståhle (2000:37) postulates that all enterprises have a mechanistic, organic and dynamic nature and that this influences how knowledge is exchanged between the participants in the enterprise. Important is the recognition that the enterprise environment plays a major role in knowledge exchange and it should be accepted as a characteristic in the process of attempting to define knowledge management. Snowden (2000:38) states that to actively manage intellectual assets, management needs to bring together, in a sustainable and appropriate environment, the explicit knowledge artefacts and the tacit knowledge communities. According to Nonaka and Takeuchi (1995:74) "the most crucial element of corporate strategy is to conceptualize a vision about what kind of knowledge should be developed and to operationalize it into a management system for implementation”.

Davenport and Prusak (1998:ix) state that for knowledge enterprises it is of critical importance to establish a link between knowledge management and the business strategy. They propose two approaches to this requirement: Make knowledge the product of the enterprise by redefining existing products and services on the basis of knowledge assets or augmenting their application with knowledge, and/or implement a business strategy with an integrated knowledge management programme ensuring that the key business drivers are supported.

This then implies that enterprises need to ensure that it applies all that it knows and considers relevant to its strategic planning process culminating in an internal and external gap analysis.

The knowledge provider perspective rather than the knowledge receiver perspective is emphasised in most studies on knowledge sharing and knowledge management (Usoro \& Majewski, 2009). McElroy (2000a:43) provides a clear overview of the differences between knowledge management supply and demand. The supply-side of knowledge management is associated with the deliveryoriented assumption that valuable knowledge exists within the enterprise and that it is the task of management to find it, codify it and deliver it. This is then followed by an approach which determines how it is to be distributed, e.g. via learning, databases and documents and to whom. Demandside knowledge management is initiated with an approach requiring a view of where valuable knowledge exists within the enterprise, whether the knowledge supports the enterprise's strategies and how it can benefit the enterprise's competitive advantage (McElroy, 2000b:200).

Wiig (2002:2) refers to 'demand pull' and 'supply push' approaches to knowledge management. Demand pull relates to management practices and approaches to capitalise on the intellectual capital of the enterprise. This focus needs to be supported via cultural, social and market place interventions - the emphasis is not on technology per se. Supply push relates to the application of technology and related developments to support the knowledge management effort in the enterprise.

Malholtra (2004:2) uses the terms 'technology push' and 'strategy pull' by questioning the increase in failures of knowledge management technology implementations and attributes this to the knowledge gap between inputs, business processes and business performance. Malholtra posits that the disconnection between technology and knowledge application is the cause of a number of challenges to knowledge management. To counter the impact of these he proposes an approach which he refers to as the Real Time Enterprise model and postulates that this model encompasses desirable knowledge management attributes such as the ability to be agile, to be responsive, to be able to anticipate future knowledge requirements and to then reconcile this with sense-making and information processing capabilities. 


\section{Just-in-time concept}

The JIT approach is focused on the elimination of waste in production systems. Waste is usually defined as defects, excess inventory, queuing due to time delays and production idleness (Clements, Crober, Thompson \& Tighe, 2008:1). Waste can also be viewed as any activity which adds cost without adding value to the production of the item. This approach can be summarised as the production of the right part at the right place at the right time - JIT is applied especially to repetitive production processes.

JIT is a management philosophy originally applied by the Japanese since the early 1970s in a large number of their manufacturing enterprises. The main proponent in the beginning was Taiichi Ohno with Toyota, the motor manufacturer, as a major development site for JIT. Macro thinking, at that stage, focused on the ability to meet consumer requirements / demand with the minimum delay(s). This perspective was later more closely viewed as a process involving having the right items of the appropriate quality and the correct number available for use at the appropriate time.

Toyota soon realised that JIT would only be successful if every individual in the enterprise was involved and committed to it. The same holds for quality processes, plant and applicable processes being set up for maximum efficiency and production programmes set up to meet exact demand requirements.

The role of Japanese culture is considered to have played a large role in the success of JIT. The Japanese work ethic can be summarised as follows (Clements et al, 2008:2):

- High motivation to seek constant improvement

- Encouragement of group effort

- Paramount priority of work over leisure

- $\quad$ Life-long employment, and

- $\quad$ Equality among race.

However, the thinking that JIT can only be successfully applied where a Japanese work ethic and culture exists is flawed and Hutchins (1989: 131) refers to Japanese companies that have established operations outside Japan, achieving similar harmonious labour relationships using indigenous work forces. In a number of cases these nonJapanese enterprises have been found to outperform their Japanese counterparts. There is then no genealogical feature inherited by the Japanese that makes them more successful at the application of JIT than other cultures.

From a macro-enterprise perspective the objectives of JIT are (Clements et al., 2008:1) to improve the competitive position of the enterprise, to increase the efficiency of the applicable production processes, and to reduce the levels of waste, in respect of materials, time and effort in the overall production process.

Hutchins (1989: 7) highlights a number of issues that have an impact on the implementation and management of a JIT approach to manufacturing. Some of these are:
- $\quad$ JIT is not just a term, but represents an enterprise goal in terms of the elimination of excess inventory.

- JIT requires a fundamental change in management thinking and enterprise cultural values.

- $\quad$ Successful JIT represents a long-term goal.

\section{JIT supply chain management perspective}

In the past enterprises produced what they thought their customers wanted and at a quality standard they considered to be acceptable to their customers. In addition, owing to management's centralist view of its importance in the process from input to output, the relationships between enterprises and their suppliers often became strained, resulting in costly production processes, poor quality and the resultant impact on the consumers / users of its products and/or services.

During the latter part of the 1970s large manufacturing enterprises in the United States and Europe started to lose their substantial market share in the global electronics and automobile industries to the Far East. Products from the latter were cheaper, at a quality level acceptable to users and, most importantly, addressed the needs of their customers. This then forced the United States and others to review the manufacturing approaches used by especially the Japanese industries. Some of these approaches were Total Quality Management (TQM), Just-in-Time manufacturing philosophy (JIT) and Quality Function Deployment (QFD).

The adoption of these approaches and others culminated in the establishment of the concept of supply chain management by large Western industrial enterprises. Supply chain management can be condensed to a process initiated at the supply of raw materials via a transformation process until the final product / service is delivered to the customer. At every node on the chain informed decisions must be taken, based upon readily available and appropriate information. The benefits to be gained relate to cost reduction, improved decision making and the optimisation of the use of resources to ensure that the enterprise maintains or improves its competitive position, collectively supported by an improvement in overall efficiency.

\section{JIT knowledge management perspective}

JIT knowledge management is an endeavour to optimise the supply of knowledge to the demand for knowledge and is based upon the analogous supply chain management concept of JIT. The research done by Metis is aimed at eliminating or managing the mismatch between knowledge demand and knowledge supply in an enterprise, as this is viewed as a major bottleneck in the application of knowledge management per se (De Jong \& Wagenaar, 2003: v). To reinforce the demand side of JIT knowledge management, Snowden (2002:10) states that "The issue is that even if we knew what we know, we cannot distinguish in advance what we need to know as an organisation, and critically when we need to know it”. What gave rise to this potential approach to managing knowledge in business was that databases were full of information. Whether the use of this could or would 
add value or not, retrieving it and searching for it became cumbersome and users did not really know how to apply it once retrieved. An analogy is that of an enterprise's warehouse rapidly filling up with inventory. Supply to the warehouse would soon exceed demand and this excess inventory would tie up working capital, slow down the overall supply process and eventually have an impact on the enterprise's competitive advantage. The objectives of the research by Metis (d'Huy, Van der Hulst, De Jong, Kleberg, Van der Niewenhuyzen, Verdoorn \& Wagenaar, 2002: v) were set as:

- $\quad$ Synchronising knowledge needs with respect to timing between different business processes and availability of knowledge resources.

- The development of appropriate methodologies to establish when specific knowledge will be required by the business.

- Optimisation of the knowledge processes by ensuring that the experts required are available to suit the time requirements for the specific knowledge required by the business.

Metis (d'Huy et al., 2002: vi) also defined some limits to their original research. These were:

- $\quad$ Not all knowledge required in an enterprise is required on a JIT basis - that used by primary processes should have preference.

- The competencies available and the competencies needed in the enterprise need to be determined to optimise the match between the competencies required and those available.

- The starting point for the transformation or closing the gap between knowledge supply and demand is the "discrepancy between the supply-side and the demandside”.

Metis used a definition of knowledge management appropriate to their approach. This is a definition by Van den Kroonenburg (d'Huy et al., 2002: 22) that states "knowledge management is bringing the right knowledge, in the right quantity, at the right place in the right time (JIT)". Using this definition then indicates acceptance that there is a relationship between time, knowledge demand and knowledge supply. Wiig's (2002:2) analysis of demand pull and supply push (discussed in a previous section) assists in understanding the JIT knowledge management concept as it refers to areas of convergence between these two approaches based upon the role of people, technology and the focus of the enterprise on managing knowledge.

The basis of the Metis model is the premise that all tools used to balance demand and supply are encapsulated in the transformation process, irrespective of organisational level. Metis refers to supply side tools such as inventories of knowledge (Yellow Pages), skills and competencies. Snowden (2002:10) refers to the use of storytelling, e.g. some member of a community may relate to a story about something, there may then be a demand for more information about the actual situation described in the story, and this may eventually find its way to a formalised document to ensure that the knowledge is not lost and is used. Likewise on the demand side there are business activities such as business intelligence, strategic planning and so forth (a very good example is the demand-side planning systems used by utilities for long and short term demand forecasting). The transaction process relates to the decision as to which tool is to be used in the transformation process and also takes into consideration the cost of doing so. The process of knowledge transformation happens within the context of the enterprise and again may happen at all or any of the business levels within the enterprise. During discussions Metis changed their view on the role of transformation and this was then deferred for inclusion into further research to be undertaken. After consultation and discussions with a number of industry representatives Metis made three changes to their original JIT knowledge management model. The revised Metis model illustrates that as the level of inventory increases over time between the various stages of the manufacturing process, there is a concomitant increase in the associated financial and other risks. The objective then is to keep the inventory at the absolute minimum level required to satisfy the demand of the following stage in the process and in that way drive down the cost of working capital over time. Each of the major elements contain planning on a continuum which is influenced by time, i.e. long term, medium term and short term. In addition, each of the elements will involve various levels of management, since each have peculiar time requirements because of the nature of the planning involved (as also referred to by Regan, 1999: 10). The relationship between the planning horizon and JIT knowledge is paramount. Knowledge that is available and not used is expensive and has a limited shelf-life. Knowledge that is required and not available inhibits the enterprise or more specifically, causes the actual level of activity to be inadequate or non-existent. Metis realised this after a number of discussions with industry and the work group developed a matrix indicating the nature of planning and thus time requirements vis-à-vis the organisational hierarchy level in the enterprise. The time horizon periods applied by Metis are long term, which is one to five years, medium term, which is one month to one year and short term, which is less than one month (De Jong \& Wagenaar, 2003: 30).

Research by Metis indicates that the primary requirement for JIT matching is on the tactical level. At top management level the time horizon is influenced by strategic considerations, implying that adequate time to demand the required information is available. De Jong and Wagenaar (2003: 14) state that at the strategic level "The Just-in-Time aspect is seen as less relevant because there is time enough to react to changes in the environment and adjust the knowledge supply". This is a serious underestimation of the nature of the environment within which strategic management is applied. At the lowest level in the enterprise, that of the work force, the information required is repetitive and whilst relevant to a degree, the possibilities of applying JIT principles are limited (De Jong \& Wagenaar, 2003: 14). In the process of developing their model further, the Metis team (De Jong \& Wagenaar, 2003: 17) did a comparative 
analysis exercise to determine the characteristics of physical and knowledge logistics.

In comparing the physical logistics to the knowledge logistics, the nature of the product to a large extent dictates the differences. For example: when a physical item is shared, ownership is lost, yet when knowledge is shared ownership still resides with the originator. When inventory is used, it reduces, yet when knowledge is used the inventory in fact increases since additional information may become available. Production processes and their particular characteristics are predictable; knowledge is humandependent, which raises the unpredictability factor. On the other hand, the cost of excess physical inventory in terms of working capital is high and so is the cost of unused or superfluous knowledge kept in repositories or databases.

De Jong and Wagenaar (2003: 18) summarise the research on the suitability of JIT methodology for knowledge management as follows: The knowledge domain introduces a degree of unpredictability into the JIT process, whereas in the logistics process JIT is subjected to a stable and predictable demand pattern. Physical logistics focus more on the Assemble to Order concept whereas JIT knowledge management focuses on the Design to Order concept.

On the demand side, the focus area is clearly at the tactical level and the issues at the operational level are reactive. On the supply side, again, the focus is more on the enterprise per se at the tactical level, whilst the long term view is based upon a host of information being supplied, which will need to be filtered to suit whatever purposes the enterprise deems to be of importance. As with the knowledge demand side, the choices are limited at operational level on the supply side. The knowledge inputs are related to repetitive, iterative approaches and very specific requirements dictated to a large extent the immediate needs of the enterprise.

The role which the Metis research plays in developing JIT knowledge management is important, as they have had a number of dedicated researchers applying their thinking to the development of JIT knowledge management models and the underlying theory over the past three years. The departure point of their research is important in that it equates knowledge management with inventory in terms of the cost of keeping unused inventory and the scarcity factor necessitating that knowledge be kept and managed at its essential minimum. Metis also delineates the fact that JIT knowledge management cannot be applied to all knowledge in an enterprise - the cost of doing so would become exorbitant. The most important aspect of the early research was to try bringing knowledge supply and demand into equilibrium. Various optimisation models were developed and aligned to phases in the logistics chain to determine which phase would best suit the analogous application of JIT knowledge management. The latest available research by Metis indicates that they have considered the impact of factors other than time that influence the application of JIT knowledge management. The one question the Metis model does not resolve is how the model addresses the time differentials between the various major elements of the model, for example the alignment between transformation, organisation and future planning horizons. Are the same planning parameters applied for short-term demand as for long-term demand, and if not, why not? The fact that these issues are not adequately addressed is a major shortcoming in the present model. The net result of this latest research is agreement by the Metis research group that knowledge is unlike logistics JIT. Demand is to an extent unpredictable and knowledge, at present, is more focused on delivering results according to specific requests for specific knowledge than a situation where knowledge is collated and delivered on an as-and-when-'ordered' basis. The implication is that JIT knowledge management is tailored to very specific circumstances and in fact should only be considered where it can be applied to the mission-critical requirements of the enterprise. Ways of application can be found in development of new products, research and development, and improvement on processes and procedures (King, Chung \& Haney, 2008: 170).

\section{JIT knowledge management approach at Eskom}

\section{Methodology}

The purpose of the empirical survey was to determine the potential for the development of a JIT knowledge management model at Eskom. Eskom, an electricity utility, can be described as a technology-oriented enterprise with emphasis on the quality of electricity supply, the concomitant development of its employees and a corporate desire to remain at the forefront of many areas of the electricity energy business, e.g. cost of generation, safety and development of appropriate as well as cutting edge technology. To this end Eskom has innovation as one of its core corporate values. In 2008 the enterprise employed 30 000 employees and had an annual turnover of R36 307 million.

A total of 355 Eskom employees were randomly selected to form the sample of this study. A questionnaire was compiled using the research by Ruggles (1998), Carrillo, Robinson, Al-Ghassani and Anumba (2004), Sarnoff and Winner (2003) and Jacobson and Prusak (2006). From this research, questions were identified that covered the theoretical constructs of JIT knowledge management. A draft questionnaire was given to a number of respondents for comment as to their understanding of the questions, length of the questionnaire in terms of time required to complete and ease of returning the completed response via e-mail. The questionnaire was e-mailed on 4 October 2007 and the 355 respondents were given until 14 October 2007 to respond. A follow-up exercise was conducted on nonrespondents in an endeavour to improve the response rate. Of the 355 addresses on the list, sixteen were returned as undeliverable, with reasons ranging from the contact being on leave or the employee having recently left Eskom, leading to the suspension of the user's e-mail address for security reasons in terms of company policy. Eight questionnaires were also physically handed to Eskom employees for completion. Thus $363(355+8)$ questionnaires were distributed and 16 requests were not responded to for valid reasons, yielding 347 (363 - 16) valid questionnaires issued. Hundred and twenty two questionnaires were completed and returned in time, which represents a response rate of 36,16\%. 
All responses received were collated centrally and forwarded to the Statistical Consultation Service (Statcon) at the University of Johannesburg, for further analysis.

\section{Research findings}

Credibility of the research was measured by the Cronbach Alpha Coefficient and the scale employed is $0 \%$ to $100 \%$, with the higher percentage indicating a higher credibility rating. The individual sets of questions in the research questionnaire were rated as per Table 1. An overall coefficient of $78,7 \%$ was calculated for the results obtained and this is considered to be in the range of scores considered as being reliable.

Table 1: Reliability statistics employing Cronbach's Alpha

\begin{tabular}{l|c|c|c}
\hline Question(s) & $\begin{array}{c}\text { Cronbach's } \\
\text { Alpha }\end{array}$ & $\begin{array}{c}\text { Cronbach's Alpha } \\
\text { Based on Standardised } \\
\text { Items }\end{array}$ & $\begin{array}{c}\text { Nu of } \\
\text { Items }\end{array}$ \\
\hline $1 \mathrm{a}-2 \mathrm{a}$ & 0,653 & 0,654 & 2 \\
\hline $1 \mathrm{~b}-2 \mathrm{~b}$ & 0,342 & 0,343 & 2 \\
\hline $1 \mathrm{c}-19 \mathrm{c}$ & 0,751 & 0,753 & 18 \\
\hline $1 \mathrm{~d}-2 \mathrm{~d}$ & 0,237 & 0,244 & 2 \\
\hline $1 \mathrm{e}-16 \mathrm{e}$ & 0,802 & 0,780 & 16 \\
\hline $1 \mathrm{f}-22 \mathrm{f}$ & 0,619 & 0,662 & 22 \\
\hline All & 0,787 & 0,783 & 63 \\
\hline
\end{tabular}

Knowledge management reflected in the enterprise's strategies, policies and practices

The overall results of this question indicate that the majority of respondents view the role of knowledge management in the enterprise's strategies, policies and practices as being of importance and to be encapsulated therein by senior management. Nearly $78 \%$ of the respondents viewed the level of importance as being either to a "great extent" or to a "very great extent". There were no responses indicating a "not at all" view. This question requested a view on the respondent's perception of whether the enterprise is in fact subscribing to the principle of having knowledge management as an integral part of its planning, strategies and work practices. A tendency or manifestation of a situation which supports this view, as the result in fact indicates, facilitates a major contribution to the potential of successfully introducing suitable and/or appropriate knowledge management systems. This is consistent with Du Plessis' (2007:99) argument that the knowledge management strategy should be tied to the business strategy for it to be successful. The shift towards JIT knowledge management or real time knowledge management should be facilitated by not having to first expose the enterprise to the benefits of knowledge management and its subsequent contributions.

\section{Knowledge management JIT definition}

Respondents were asked to what extent they agreed with the definition of knowledge management by d'Huy et al.
(2002:22), considering their present work situation: "Knowledge management is bringing the right knowledge, in the right quantity, to the right place at the right time". This specific definition, in the respondents' present work situation, is viewed by $74 \%$ of them as either applicable to a "great extent" or to a "very great extent". There were no respondents returning a "not at all" response. The definition used is the classic knowledge management JIT definition and the high score indicates that in a situation where this definition is the modus operandi, it will have the support of the majority of the workers.

Cross-tabulating the results in respect of respondent's perspectives on the knowledge management JIT definition is shown in Figure 1, which reflects the scores of the various Eskom divisions. Whilst the percentage of respondents that indicated "not at all" is high in the Distribution (Distr) and Enterprise (ED) Divisions, the actual number [No] is low. The relatively high scores [No] in respect of Enterprises Division is encouraging. Scores of respectively 8 (35\%) for "somewhat" and 22 (40\%) for "great extent" indicated a high degree of acceptance of the definition as posed. Of the 121 valid responses for this question, $89(73,6 \%)$ of the respondents returned a score in the categories "great extent" or "very great extent".

Evolution of the role of knowledge management in the enterprise strategy formulation process

Traditionally many companies have taken an ad hoc approach to managing knowledge, resulting in work duplication, inconsistent work practices and loss of important organisational knowledge when employees retire or leave the company (Du Plessis \& Du Toit, 2006: 360). Out of the total population, $84,3 \%$ of the respondents agreed, to one extent or another, with the statement that a knowledge management strategy is the result of an evolutionary process rather than the result of a direct and interventionist approach by senior management. This reflects a lack of co-ordinated effort by management or a situation where non-integrated and uncoordinated pockets of knowledge management initiatives exist within the enterprise. The results of the analysis indicate general consensus that knowledge management came about via evolution rather than direct management intervention. This finding is confirmed by Mostert (2006:8) who stated that formal knowledge management is still in a process of evolution and that a knowledge management strategy is of little benefit unless they are usable by people in enterprises. The divisional results indicate pockets of knowledge management rather than an integrated approach in the enterprise. From a JIT knowledge management perspective or any other knowledge management initiative, this presents a considerable obstacle to the success of any project. An approach will be to isolate a division where the successful implementation of a knowledge management initiative can be shown to have made a considerable contribution and will be of such a magnitude that it can be sold as a success story in other divisions. 


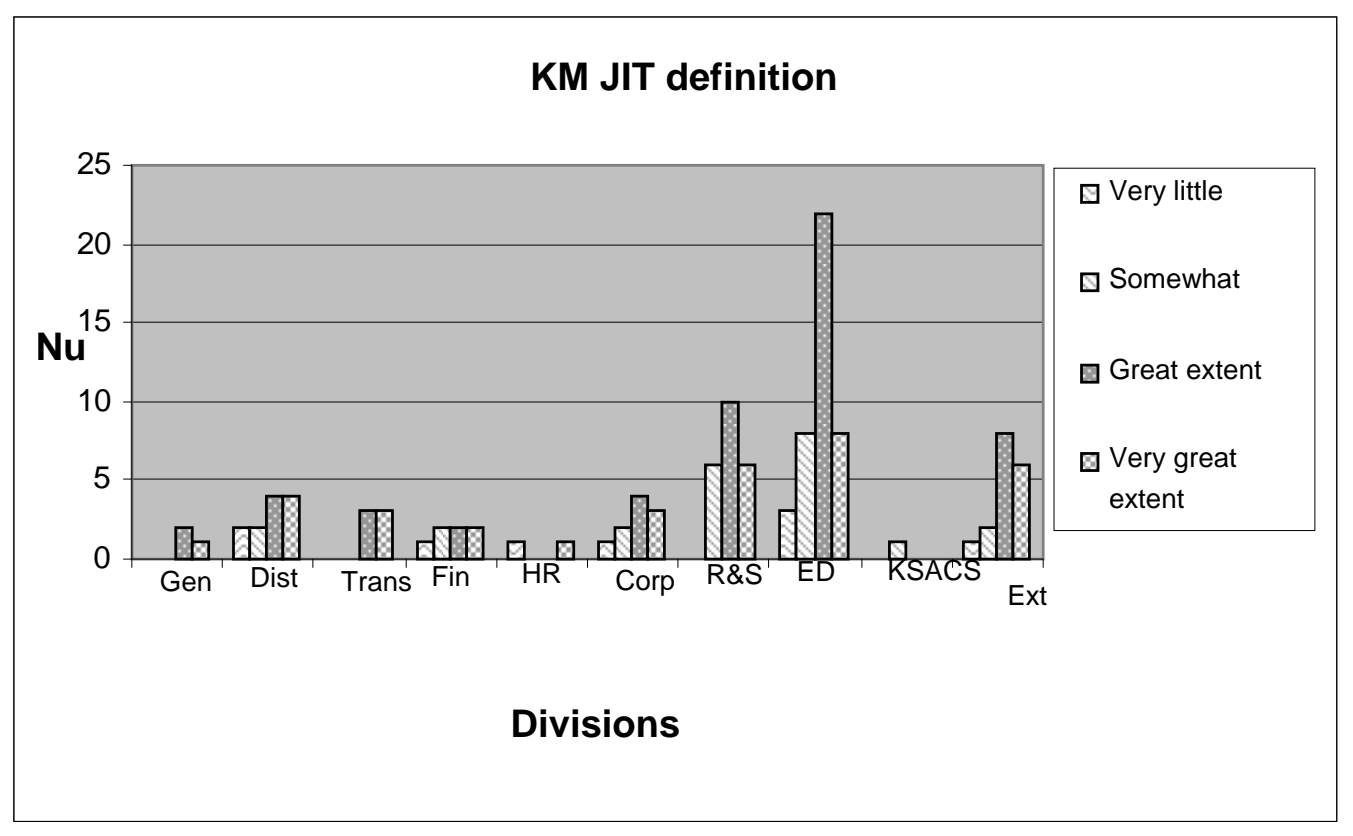

Figure 1: Agreement with KM JIT definition

Inability to measure the real contribution of knowledge management

Respondents were asked to compare the following statement with their present work situation: "The inability to measure the real contribution of knowledge management on strategic outcomes is an inhibiting factor to acceptance of its role in strategic planning”. The basis of the question relates to the saying, "what gets measured gets done". More than $95 \%$ of the respondents agreed that because knowledge management, in general, does not get measured, this is an inhibitor to its acceptance and thus effective deployment in the enterprise.

\section{Internal processes geared to future demand of knowledge}

Respondents were asked to indicate to what extent they agree with the statement: "There are internal processes geared to providing the enterprise with a view as to the potential future demand for knowledge, both internal and external to the enterprise". The question not only relates to an employee's present work situation, but can also reflect a perspective on the enterprise's approach to a JIT knowledge management model.

According to Figure 2, the majority (69\%) of the respondents indicated that in their view the internal processes in the enterprise are not geared to respond to future demand for knowledge. Only 30\% of the respondents are of the view that the enterprise is prepared either to a "great extent" $(22,1 \%)$ or to a "very great extent" $(2,5 \%)$. In the categories "not at all" (6,6\%) and "very little" (38,5\%) the enterprise is viewed as unprepared for whatever knowledge demand requirements the future may impose on it. These findings are in contrast with the findings of Kulkarni, Ravindran and Freeze (2007:342) at a technical institution that the organisational support structure was a contributing factor to the success of knowledge management.

\section{Knowledge managed like physical inventory}

The questions required a view from the respondents as to whether, like physical inventory, knowledge should be managed considering factors such as the cost and scarcity of knowledge. It presupposes the application of a methodology supported by technology to achieve this. Fifty-five percent of the population agreed that it should be managed in a similar manner. This is just more than half of the population with $38 \%$ responding that it should not be the case (see Figure 3). This result is perturbing and any knowledge management initiative will have to take a perspective indicating such an unfavourable disposition towards JIT principles into consideration. 


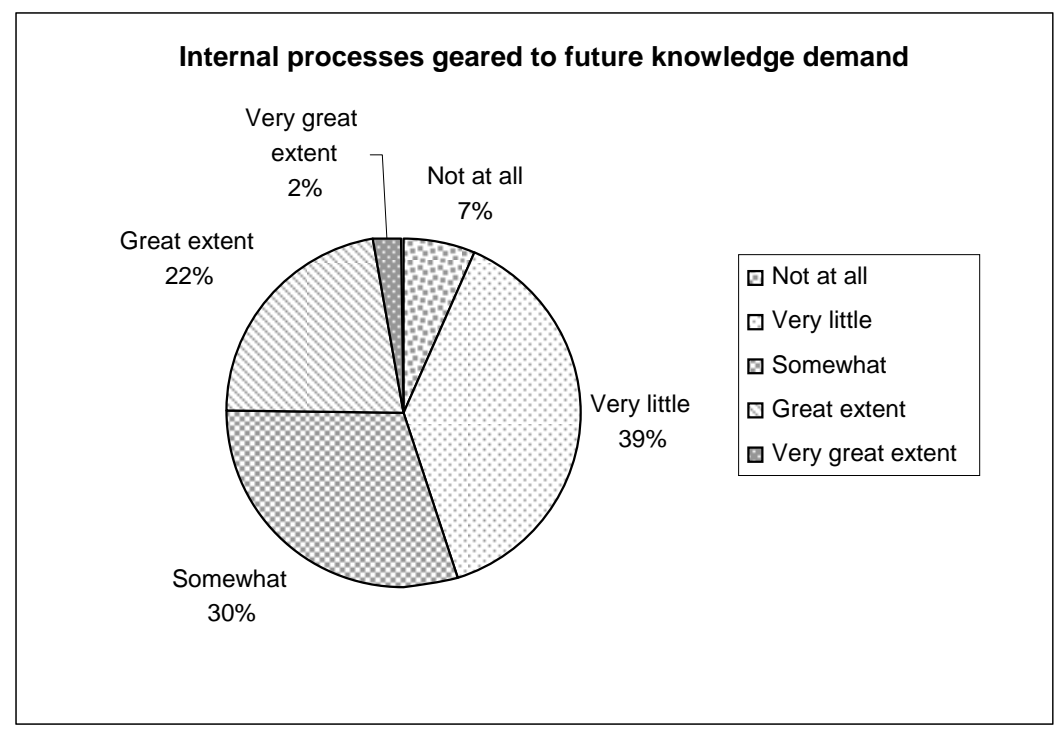

Figure 2: A view as to whether internal processes are geared to future demand for knowledge

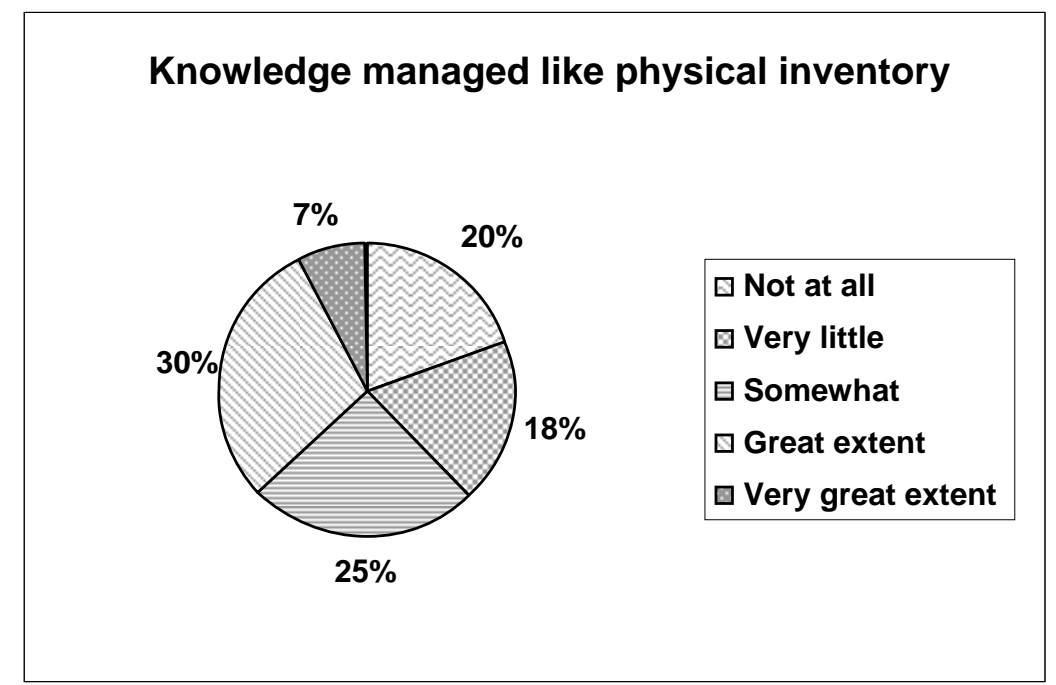

Figure 3: Knowledge management like physical inventory

The responses to the set of questions dealing with the definition of knowledge management indicated that the respondents considered it important that knowledge management should be reflected in the enterprise's strategies, policies and practices. There was also extensive support for the JIT knowledge management definition of bringing the right knowledge, in the right quantity, to the right place at the right time. In respect of knowledge management in the organisational context there was general agreement that what can be considered as knowledge management at present in the enterprise is as a result of evolution rather than direct intervention by management. The lack of metrics and thus the inability of measuring the bottom-line impact of knowledge management are viewed as an important factor inhibiting its acceptance as playing a role in strategic planning. The view was expressed that the enterprise is not really geared to future demand for knowledge and that the knowledge workers are sensitive to this shortcoming. The response from those engaged in information management activities is of concern. Fortyseven percent of this group indicated that knowledge should be managed in a similar manner as physical inventory. The implications for JIT knowledge management are paramount, as this is the conceptual basis of the approach. This is the group of knowledge workers that will be responsible for managing any technology platform that is applied, as well as maintaining it and improving its future capabilities.

The deployment of technology for an enterprise Yellow Pages

This question relates to the respondents' viewpoint on the employment of technology with the object of mapping available experts in the enterprise, making their profiles retrievable through user-friendly search engines and providing up-to-date contact information, i.e. an enterprise Yellow Pages. More than $90 \%$ of the population agreed that technology should be employed to deploy an enterprise Yellow Pages application. This is of interest, as the enterprise at present deploys a Novell GroupWise application for e-mail communication, which does have an effective "Address Book" functionality. The addition of 
some additional personal information in respect of a specific person can obviate the need for a totally new application to act as a Yellow Pages platform.

\section{Knowledge contribution and hierarchical position}

This question relates to the opportunity to contribute knowledge created by a knowledge worker's hierarchical position in the enterprise. This is based on the belief that people who know more tend to be more powerful than those who know less (Du Plessis, 2007: 93). More than 84\% of the respondents were of the opinion that a worker's hierarchical position contributed to the opportunity of the worker for making knowledge contributions. This view must be considered in relation to the perception that the higher an employee is on the "organisational ladder", the more knowledgeable that employee is and thus the greater his or her contribution. This finding supports the findings of Mostert and Snyman (2007) that senior management has an impact on knowledge management practices in an enterprise. This is a perception that will need to be managed, hence the requirement that the importance of knowledge management must be demonstrated and executed by senior management. It should be addressed in any knowledge management initiative via methods such as Communities of Practice, workshops, seminars and conference attendance and task group assignments.

\section{Knowledge interaction and time spent on it}

This question reflects recent information on how the respondents, as knowledge workers, spent their time. Figure 4 reflects that time spent on knowledge interaction is ranked, firstly, as relating to searching for new knowledge, secondly, as adapting knowledge gained and thirdly, as eliciting knowledge from experts. Fifty percent of the respondents search for new knowledge to 'a great extent' and $40 \%$ indicated that they have to adapt new knowledge gained to a great extent.

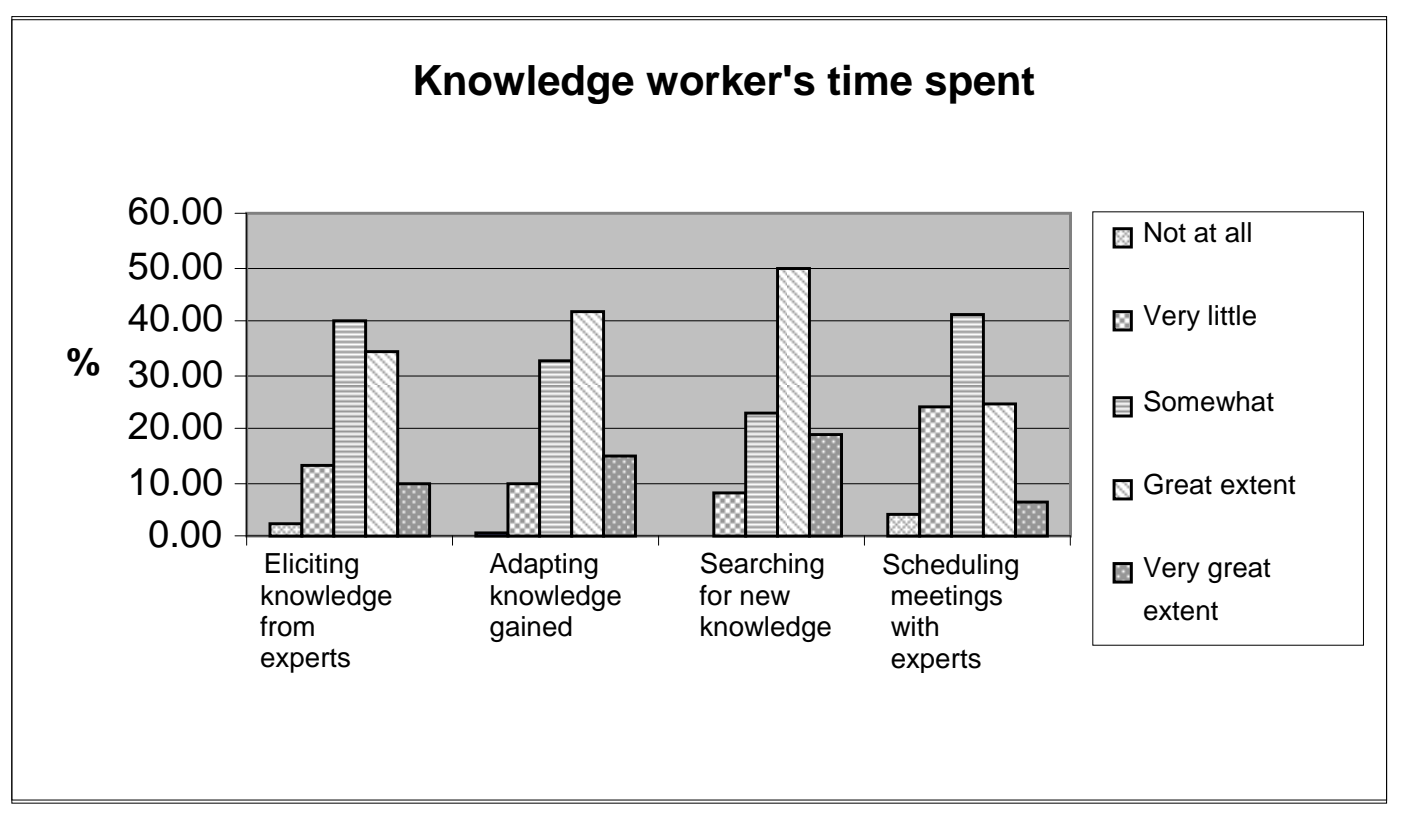

Figure 4: Knowledge interaction

\section{Recommendations}

The empirical results indicate that any knowledge management initiative will need to take cognisance of those areas where there is general agreement that the current enterprise status is unacceptable. In addition, there are issues that will either inhibit or impede the potential for JIT knowledge management as well as real-time knowledge management. In determining the potential for the development and implementation of a JIT knowledge management approach analogous to that of the logistics model, cognisance needs to be taken of a number of issues influencing a wide range of domains and variables within the enterprise. These are the areas of enterprise strategy and the acceptance of a definition of knowledge management which emphasises its role in such a strategy and issues associated with the application of knowledge in the enterprise in a number of business areas. The analysis of the responses indicates an overwhelming view that in terms of their present work situation the respondents regard it as essential for management to recognise and incorporate this role of knowledge management into its strategic planning and then evolve it further down in terms of the enterprise's policies and practices.

The view of Furlong (2003: 13) is that knowledge management is a business activity with two principal elements, one which is directed at being encapsulated in the enterprise's strategies and secondly, an acceptance that knowledge management contributes to the enterprise's bottom line. The logical conclusion is that knowledge management can only contribute to the success of the business if it is allowed to influence the bottom line and an approach to ensure that it does so is engaging knowledge management at the highest levels of the enterprise. 
From a JIT knowledge management perspective this problem can only be addressed if the enterprise is aware of its future knowledge requirements and hence, can plan, to the most accurate extent possible, what its knowledge requirements will be. It is accepted that the enterprise environment is dynamic, but to a large extent the requirements for a two or three year strategic business plan for example are known and the gap between existing knowledge and the required knowledge can be assessed and attempts made to mitigate the situation. This is not difficult per se and such an endeavour complies with the concept of having the right knowledge available when needed.

The knowledge management definition which best fits the research objective is that of d'Huy et al. (2002: 22), as it optimises the relationships between the elements of delivery time, right knowledge and the right person to enact the knowledge. The research population responded positively to the statement and this will ease the acceptance of such a concept, thus facilitating its implementation; all things being equal in terms of factors such as user-friendliness, valueadding to the enterprise, the "what is in it for me?" syndrome and similar issues.

From a demand versus supply-side knowledge management perspective the research population indicated that the internal processes of the enterprise are not geared for future knowledge requirements and thus demand for knowledge will be stochastic and it is probable that whatever is required will not be provided when required. JIT knowledge management has as a pre-requisite the ability to forecast what knowledge is required, when and to whom it must be directed.

In respect of the management of knowledge in a manner similar to that of a physical inventory, in view of the attributes of scarcity and cost of storage the research population indicated that they do not believe that there is a very strong positive relationship between the logistics approach and JIT knowledge management. The likely impact of this perception is that the emphasis on managing "down" large data repositories to the level where they constitute current, valid and usable information will require considerably more effort than if the research population were sensitive to the cost drivers. Other negative effects of large repositories are, for example, information overload, difficulty in searching for the required information and time expended in doing so.

The lack of suitable metrics to measure the knowledge management contribution and thus its cost plays a major role in the enterprise not being sensitive to the analogy between knowledge and physical inventory. The potential for demand-side knowledge management does exist and there are proven expectations that it will enable the knowledge worker. However, the challenges in existence in the enterprise, the perceptions which will need to be changed and managed as to the analogous nature of JIT knowledge management to physical inventory and management's lack of demonstrated involvement in the knowledge management effort do present formidable potential obstacles to the successful implementation of such an initiative.
The research population indicates that in terms of time spent the highest demand is created by searching for new knowledge, then by adapting knowledge gained and then by eliciting knowledge from experts. The analysis of the variables exerting an influence on the ability of the enterprise to enhance the contribution of knowledge management or having the potential to do this covers a number of aspects that need to be managed in an integrated manner. The major components relate to the optimisation of the role of knowledge management in the enterprise strategy, the transfer of knowledge and the optimisation of the contribution of the knowledge worker. Irrespective of whether a JIT knowledge management model is introduced or any other knowledge management application, such as a real-time application or an enterprise Yellow Pages application, the factoring of the three major components needs to be recognised and integrated to achieve a successful outcome.

The research by Metis locates JIT knowledge management only in terms of one or two possible stages in the logistics chain. In addition, their research indicates that JIT knowledge management will need to be tailored to very specific requirements for specific information, which because of its nature will be costly and can thus only be justified for use in applications that warrant the effort in terms of time and cost. The example of the use of JIT knowledge management in a hospital database and associated support for decision-making by medical practitioners provided by Davenport and Glaser (2002: 108) typifies the potential kind of application possible.

Real-time knowledge management introduces the concept of latency of information and this allows for reduced cost and a measure of storage of information until required. It increases the time between the event and the related decision to be made. The possible applications are also in less critical business applications and leverage technology to a greater extent than JIT knowledge management. However, it is still subjected to all of the variables which have an impact on JIT knowledge management and the need to manage these is therefore as critical as in the case of JIT knowledge management.

\section{Conclusion}

In view of the findings certain recommendations were made for Eskom. Although these recommendations are based on the findings from one enterprise in the South African context, they may be relevant to any enterprise in an international context. The potential to develop and implement a JIT knowledge management model exists in Eskom; however, it is subject to a number of extraneous and internal variables present in the enterprise's environment and within the enterprise. The variables external to the enterprise relate to the dynamics of its operating environment that have an impact on its competitive position and for JIT knowledge management to be successful the ability to improve the accuracy and timing of future information requirements is essential.

The number and extent of internal variables that have an impact on the possible development and implementation of 
JIT knowledge management makes its general use impractical from a cost and development perspective. There are, however, areas within the enterprise where management should consider the use of JIT knowledge management, specifically in strategic planning via the use of scenario applications, applications in niches where the competitive position of the enterprise will be enhanced by the specificity of knowledge obtained and used and where the cost of doing so is offset by the gains in enterprise performance. The fallback position if JIT knowledge management cannot be realised is the application of the principles of real-time knowledge management, which are more technology-reliant. This would create the potential to reduce the importance and role of the knowledge worker in the final application of the knowledge gained, namely the taking of an appropriate decision.

\section{References}

Bateman, T.S. \& Snell, S.A. 2007. Management: Leading and collaborating in a competitive world. New York: McGraw-Hill Irwin.

Carrillo, P., Robinson, H., Al-Ghassani, A. \& Anumba, C. 2004. 'Knowledge management in UK construction: Strategies, resources and barriers', Project Management Journal, 35(1): 46-56.

Clements, P., Crober, G., Thompson, C. \& Tighte, K. 2008. 'Operations research - JIT Production Systems'. [online] URL:http://www.dal.ca/ qhe/ie113398/jit html. Accessed 4 May 2008.

Davenport, T.H. \& Glaser, J. 2002. 'Just in time delivery comes to knowledge management', Harvard Business Review, 80(7):107-111.

Davenport, T.H. \& Prusak, L. 1998. Working knowledge: How oganizations manage what they know. Boston: Harvard Business School Press.

De Jong, K.Y. \& Wagenaar, W.J.G.P. 2003. Just in time knowledge management. The problem, a model and practical applicability of the model. (C)etis. Version 1.0. Project Reference: Metis/D2.1. Enschede: TNO Fysisch Elektronisch Laboratorium.

d'Huy, K., Van der Hulst, L., De Jong, K., Kleberg, J., Van den Niewenhuyzen, N., Verdoorn, A. \& Wagenaar, W. 2002. Just in time knowledge management. A state of the art report. CMetis. Version 0.6. Project Reference: Metis/D5.1. Enschede: TNO Fysisch Elektronisch Laboratorium.

Drucker, P.F. 1999. 'Knowledge-worker productivity: The biggest challenge', California Management Review, 41(2):79-94.

Du Plessis, M. 2007. 'Knowledge management: What makes complex implementations successful?' Journal of Knowledge Management, 11(2):91-101.
Du Plessis, T. \& Du Toit, A.S.A. 2006. 'Knowledge management in the practice of law', International Journal of Information Management, 26(4):360-371.

Furlong, G. 2003. 'Knowledge management and the competitive edge'. [online] URL:

http://www.gre.ac.uk/schools/business/Dissertation/index.ht ml. Accessed 20 December 2007.

Hutchins, D. 1989. Just in time. Hants: Gower Technical Press.

IBM. 2004. Business knowledge management: A study on market prospects, business Needs and technological trends. Basingstoke: European Commission.

Jacobson, A. \& Prusak, L. 2006. 'The cost of knowledge', Harvard Business Review, 84(11): 34.

King, W.R., Chung, T. \& Haney, M.H. 2008. 'Knowledge management and organisational learning', International Journal of Management Science, 36:167-172.

Kulkarni, U. R., Ravindran, S. \& Freeze, R. 2007. 'A knowledge management success model: Theoretical development and empirical validation', Journal of Management Information Systems, 23(3): 309 -347.

Malholtra, Y. 2004. 'Integrating knowledge management technologies in organizational business processes: Getting real time enterprises to deliver real business performance.' [online] URL:

http://www kmnetwork.com/KnnowledgeManagementReal TimeEnterpriseBusinessModels html . Accessed 5 November 2007.

McElroy, M.W. 2000a. 'The new knowledge management', Knowledge and Innovation: Journal of the KMCI, 1(1):4367.

McElroy, M.W. 2000b. 'Integrating complexity theory, knowledge management and organizational learning', Journal of Knowledge Management, 4(3):195-203.

Mostert, J.C. 2006. 'A knowledge management framework for the CSIR National Metrology Laboratory'. MIT Dissertation. Pretoria: University of Pretoria (Unpublished).

Mostert, J.C. \& Snyman, M.M.M. 2007. 'Knowledge management strategy for the development of an effective knowledge management strategy', South African Journal of Information Management, 9(2). [Online] URL: http://www.sajim.co.peer131.9nr2.asp?print=1. Accessed 23 October 2009.

Nonaka, I. \& Takeuchi, H. 1995. The knowledge-creating company. Oxford: Oxford University Press.

Regan, J. 1999. 'J-I-T Knowledge: Creating a demand-based enterprise knowledge system', Inside Knowledge, 3(2):8-10. 
Ruggles, R. 1998. 'The state of the notion: knowledge management in practice', California Management Review, 40(3):80-89.

Sarnoff, A. \& Winner, T. 2003. 'Knowledge management and intranet: Putting people first'. [online] URL:http://www.intranetjournal.com/articles/200304/pij_04 _23_03b html. Accessed 5 August 2007.

Snowden, D. 2000. 'Liberating knowledge'. In Rock, S. (Ed). Liberating knowledge. London: IBM/CBI, pp. 7-15.

Snowden, D. 2002. 'Complex acts of knowing: Paradox and descriptive self-awareness', Journal of Knowledge Management, 6(2):1-13.

Ståhle, P. 2000. 'New challenges of knowledge management'. In Rock, S. (Ed). Liberating knowledge. London: IBM/CBI, pp. 35-40.

Usoro, A. \& Majewski, G. 2009. 'A case of knowledge sharing in Finnish Laurea Labs as a knowledge intensive organisation'. In Proceedings of the 6th International Conference on Knowledge Management: Managing Knowledge for Global and Collaborative Innovations, 3-4 December, Hong Kong, China. (CD-ROM).

Wigg, K.M. 2002. New generation knowledge management: What may we expect? Houston: Knowledge Research Institute, Inc.

Yang, J. 2007. 'The impact of knowledge sharing on organisational learning and effectiveness', Journal of Knowledge Management, 11(2):83-90. 